\title{
Eficiência Nutricional e Produtividade de Milho pelo Uso de Biofertilizante Orgânico
}

\author{
Maize Nutritional efficiency and Productivity by the use of Organic Biofertilizer
}

\author{
Marlos Ferreira Dornas; ; José Antônio Maior Bono ${ }^{\mathrm{a}}$; Hélio Hiroshi Suguimoto ${ }^{\mathrm{b}}$; Denise Renata Pedrinho; \\ Aline Vanessa Sauerc; Bianca Obes Corrêa ${ }^{a}$
anniversidade Anhanguera Uniderp, Programa de Pós-Graduação Stricto Sensu em Produção e Gestão Agroindustrial. MS, Brasil. bUnopar, Programa de Pós-Graduação Stricto Sensu em Ciência e Tecnologia de Leite e Derivados. PR, Brasil.
'Unopar, Curso de Agronomia. PR, Brasil.
*E-mail: bianca.obescorrea@yahoo.com.br

\begin{abstract}
Resumo
O objetivo deste trabalho foi avaliar a influência do bioestimulante Fert Bokashi Premium ${ }^{\circledR}$ e microfiltrado sobre a eficiência nutricional e produtividade da cultivar de milho DKB 290 Pro3, em condições de campo. O delineamento experimental foi o de blocos ao acaso com onze tratamentos e quatro repetições. Os resultados indicaram ganhos nutricionais que influenciaram a produtividade de grãos, nas diferentes épocas de aplicação, plantio e foliar. Dessa forma, ficou clara a influência do produto Fert Bokashi ${ }^{\circledR}$ ativado na semeadura já que as médias foram superiores quando as aplicações ocorreram na semeadura e nos estádios vegetativos V4 e V8. Para o microfiltrado, foi obervado que os nutrientes $\mathrm{Fe}, \mathrm{Cu}, \mathrm{K}$ e S, mantiveram os níveis exigidos para a cultura, indicando que para incrementar a produtividade é necessário um aporte de nutrientes que garantem as plantas suas necessidades, e que a produtividade apresenta estreita relação com as taxas de nutrientes extraídas pelas plantas. O uso do biofertilizante Fert Bokashi ${ }^{\circledR}$ ativado aumenta os teores de $\mathrm{Fe}, \mathrm{K}$ e S, os quais interferem na produtividade de milho em condições de campo, e quando aplicado no plantio e nos estádios V4 e V8.
\end{abstract}

Palavras-chave: Fert Bokashi. Fertilizante Orgânic. Zea mays.

\begin{abstract}
The objective of the work was to evaluate the influence of the biostimulant Fert Bokashi Premium $₫$ and microfilter on the nutritional efficiency and productivity of the maize cultivar DKB 290 Pro3, under field conditions. The experimental design was a randomized block with eleven treatments and four replications. The results indicated nutritional gains that influence grain yield, at different application times, planting and leaf. Thus, it was clear the influence of the product Fert Bokashi ${ }^{\circledR}$ activated at seeding planting, with higher averages when applications occurred at seeding and in vegetative stages V4 and V8. For the microfilter, it was observed that the nutrients Fe, Cu, Kand S, maintained the levels required for the culture, indicating that to increase productivity it is necessary to supply nutrients that guarantee the plants their needs, and that productivity has a close relationship with the rates of nutrients extracted by the plants. The use of activated biofertilizer Fert

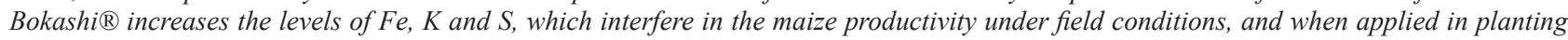
and in stages $V 4$ and $V 8$.
\end{abstract}

Keywords: Fert Bokashi. Organic Fertilizer. Zea mays.

\section{Introdução}

O milho (Zea mays L.) é o cereal mais cultivado no Mundo em função da importância econômica e social, sendo considerado como alimento energético, possui em sua composição carboidratos e lipídeos, e sua produção se estende em todo território nacional se destacando as regiões Sul, Sudeste e Centro-Oeste. Fato que destaca o Brasil como terceiro maior produtor mundial (SANGOI et al., 2016; LUDKE, et al., 2016). Essa posição foi conquistada em função de mudanças tecnológicas aplicadas para a melhoria da qualidade dos solos como o plantio direto e manejo da fertilidade com uso de fertilizantes químicos e orgânicos, gessagem e calagem (COELHO et al., 2010).

Entre os nutrientes de maior importância, o nitrogênio é o requerido em maior quantidade pelas plantas de milho, sendo o que mais limita sua produção. O macronutriente é constituinte essencial das proteínas, interfere diretamente no processo da fotossíntese, e seu fornecimento pode ser feito através de fertilizantes nitrogenados e ciclagem da matéria orgânica das culturas anteriores através da mineralização (BROCH; RANNO, 2012). No entanto, estes efeitos podem ser potencializados, pelo uso de bioestimulantes vegetais, que contém elementos de nutrição para o desenvolvimento das plantas, que adicionam ao solo micro-organismos para melhorias químicas, físicas e biológicas, além de diminuem o custo de produção para o produtor rural com adubos químicos e nas aplicações com defensivos agrícolas, uma vez que podem ativar mecanismos de defesa da planta, além do ganho na sustentabilidade do sistema (SOUZA et al., 2010).

Os bioestimulantes contêm, em sua composição, substâncias orgânicas, complexas e modificadoras do crescimento de plantas, expressão gênica, alterações de proteína de membrana e enzimas metabólicas. Por ocorrer uma alteração no metabolismo secundário da planta, em decorrência da ação dos bioestimulantes, há indução de 
precursores de fito-hormônios e síntese fito-hormonal, aprimorando uma melhor resposta das plantas aos nutrientes e melhora no desenvolvimento vegetal (SIQUEIRA; SIQUEIRA, 2013).

Os fito-hormônios presentes nos bioestimulantes podem incitar a dominância apical, pois podem conter auxinas responsáveis por esta ocorrência e também pelo crescimento vegetal, influenciando diretamente nos mecanismos de expansão celular, as citocininas que têm a função na regulagem da imobilização dos nutrientes e as giberelinas importantes no crescimento do caule, expansão no aumento das raízes o que aperfeiçoa a área de exploração do solo (SANTOS et al., 2013; TAIZ; ZEIGER, 2013a).

Já os micro-organismos podem aumentar a disponibilidade de nutrientes às plantas pelo procedimento de mineralização através da matéria orgânica do solo, e atuar indiretamente por meio do retorno dos nutrientes imobilizados pela massa microbiana (MALIK et al., 2012).

Os componentes presentes nos bioestimulantes promovem alterações nos processos metabólicos, melhorando o equilíbrio hormonal e nutricional, estimulando o desenvolvimento do sistema radicular com maior absorção de água e nutrientes (SILVA et al., 2008).

A ação mútua dos compostos orgânicos com a nutrição de plantas, relacionados com aumento da eficiência no transporte e absorção dos nutrientes, tem evidências de que os compostos orgânicos apolares, como os bioativadores, aumentam a capacidade de circulação de substância através das membranas que são polares (FLOSS; FLOSS, 2007).

O objetivo deste trabalho foi avaliar a influência do bioestimulante Fert Bokashi Premium ${ }^{\circledR}$ e microfiltrado sobre a eficiência nutricional e produtividade da cultura do milho em condições de campo.

\section{Desenvolvimento}

\subsection{Caracterização da área}

O experimento foi conduzido na Estação Experimental CropSolutions, localizada no município de São Gabriel do Oeste MS, sob coordenadas geográficas 1946'78,3'" S 5461'61,5' O; altitude $657 \mathrm{~m}$; clima da região do tipo tropical Cwa.

O solo da área experimental é classificado de Latossolo Vermelho distroférrico apresentando na camada de 0 a $20 \mathrm{~cm}$ $\mathrm{MO}=25,5 \mathrm{~g} \mathrm{~kg}^{-1} ; \mathrm{pH}=4,7 ; \mathrm{P}$ (Mehlich-1)=29 mg dm${ }^{-3} ; \mathrm{K}=$ 3,$9 ; \mathrm{Ca}=33,9 ; \mathrm{Mg}=10,8 ; \mathrm{H}+\mathrm{Al}=51,2, \mathrm{Al}=4,1 \mathrm{mmol}_{\mathrm{c}} \mathrm{dm}^{-3} ; \mathrm{S}$ ${ }_{\text {so }}=35,6 ; \mathrm{Cu}=4,7 ; \mathrm{Fe}=17,2 ; \mathrm{Zn}=2,5 ; \mathrm{Mn}=25,7 ; \mathrm{B}=0,3 \mathrm{mg}$ $\mathrm{dm}^{-3}$; argila $=507$; areia $=287$ e silte $206 \mathrm{~g} \mathrm{~kg}^{-1}$ e na camada 20 a $40 \mathrm{~cm} \mathrm{MO}=16,7 \mathrm{~g} \mathrm{~kg}^{-1} ; \mathrm{pH}=4,9 ; \mathrm{P}($ Mehlich-1 $)=5,6 \mathrm{mg}$ $\mathrm{k}^{-1} ; \mathrm{K}=2,3 ; \mathrm{Ca}=25,8 ; \mathrm{Mg}=6,3 ; \mathrm{H}+\mathrm{Al}=40,0, \mathrm{Al}=3,3 \mathrm{mmol}_{\mathrm{c}}$ $\mathrm{dm}^{-3} ; \mathrm{S}_{\text {so }}=48,4 ; \mathrm{Cu}=2,3 ; \mathrm{Fe}=10,0 ; \mathrm{Zn}=0,7 ; \mathrm{Mn}=9,0 ; \mathrm{B}=0,3$ $\mathrm{mg} \mathrm{dm}^{-3}$, argila $=523$; areia $=273$ e silte $204 \mathrm{~g} \mathrm{~kg}^{-1}$, conforme Embrapa (2009). Nesta área, o histórico é de cultivo anterior com soja.

\subsection{Dados meteorológicos}

Precipitação pluviométrica (mm), temperaturas mínimas e máximas $\left({ }^{\circ} \mathrm{C}\right)$, durante a execução do experimento na Estação Experimental CropSolutions, estão descritos no gráfico, indicando que as condições meteorológicas para região durante a execução do experimento foram consideradas adequadas.

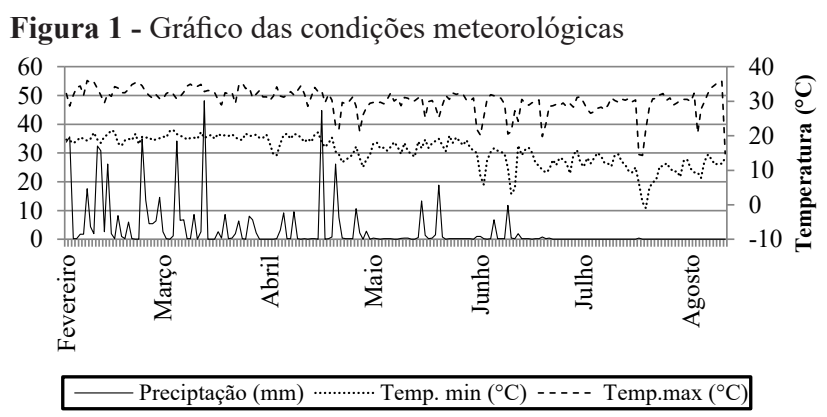

Fonte: Estação meteorológica Crop Solutions.

\subsection{Produtos}

Os produtos utilizados neste ensaio foram o bioestimulante vegetal FertBokashi Premium ${ }^{\circledR}$ fornecido pela empresa Korin Agropecuária Ltda. O produto foi ativado a $10 \%$ a partir da recomendação da formulação, em que foram utilizados $10 \mathrm{~mL}$ do produto, $100 \mathrm{~g}$ de açúcar e $1 \mathrm{~L}$ de água torneiral e, posteriormente, o mesmo foi diluído para $1 \%$ para as aplicações.

O microfiltrado foi obtido por meio da filtração do produto ativado a $10 \%$, por fluxo tangencial em uma unidade MinitanTM Microfiltration/ Ultrafiltration System (MILLIPORE). A unidade foi equipada com placas de acrílico em que foram fixadas as membranas de diâmetro de poro de 0,2 $\mu \mathrm{m}$. Cada placa tem uma área de superfície filtrante de $60 \mathrm{~cm}^{2}$, com capacidade de filtração varia entre $500 \mathrm{mLa} 2000 \mathrm{~mL}$. O fluxo foi realizado por uma bomba peristáltica que transferiu o produto à filtração de um reservatório até a unidade de filtração. As partículas maiores que $0,2 \mu \mathrm{m}$ foram retidas na superfície das membranas e retornaram ao reservatório, e novamente bombeadas para a membrana. Água, sais minerais e outras partículas menores que $0,2 \mu \mathrm{m}$ passaram pelas membranas e constituíram no permeado, também denominado extrato (microfiltrado), que foi armazenado em outro recipiente.

\subsection{Instalação, condução e delineamento experimental.}

O ensaio foi instalado, sob sistema de plantio direto, com semeadura em março de 2017, sendo utilizada a cultivar de milho DKB 290 Pro3, recomendada para a região conforme a Fundação Chapadão (2016). A adubação de base constou de $48 \mathrm{~kg} \mathrm{ha}^{-1} \mathrm{~N}$ e $68 \mathrm{~kg} \mathrm{ha}^{-1} \mathrm{P}_{2} \mathrm{O}_{5}$. $\mathrm{kg} \mathrm{ha}^{-1}$. Após 30 dias da semeadura, foi realizada adubação de cobertura em que foram aplicados $75 \mathrm{~kg} \mathrm{ha}^{-1}$ de $\mathrm{N}$ e $50 \mathrm{~kg} \mathrm{ha}^{-1}$ de $\mathrm{K}_{2} \mathrm{O}$.

Os produtos e períodos de aplicação utilizados no experimento estão descritos no Quadro 1. As aplicações dos tratamentos ocorreram via tratamento do solo, no plantio 
(Pla), os demais tratamentos, ocorreram no estádio de desenvolvimento vegetativo V4 (março de 2017) e no estádio V8 (abril de 2017). Para tanto, foi utilizado um pulverizador costal de pressão constante, pressurizado por $\mathrm{CO}_{2}$, com barra de 4 bicos com pontas do tipo leque 110.02, espaçados em 0,5m, empregando-se uma pressão de 2,4 bar e volume de aplicação de $100 \mathrm{~L} \mathrm{ha}^{-1}$.

Quadro 1 - Descrição dos tratamentos, doses e períodos de aplicação do bioestimulante Fert Bokashi Premium ${ }^{\circledR}$ na cultura do milho

\begin{tabular}{|c|c|c|c|}
\hline $\mathbf{N}^{\mathbf{0}}$ & Tratamento & $\begin{array}{c}\text { Dose } \\
\text { (L ha }^{-1} \mathbf{)}\end{array}$ & $\begin{array}{c}\text { Período de } \\
\text { aplicação* }\end{array}$ \\
\hline 01 & Testemunha & -- & -- \\
\hline 02 & Fert Bokashi Premium & 5,0 & $\mathrm{Pla}$ \\
\hline 03 & Microfiltrado & 5,0 & $\mathrm{Pla}$ \\
\hline 04 & Fert Bokashi Premium & $5,0 / 5,0$ & $\mathrm{Pla} / \mathrm{V} 4$ \\
\hline 05 & Microfiltrado & $5,0 / 5,0$ & $\mathrm{Pla} / \mathrm{V} 4$ \\
\hline 06 & Fert Bokashi Premium & $5,0 / 5,0$ & $\mathrm{Pla} / \mathrm{V} 8$ \\
\hline 07 & Microfiltrado & $5,0 / 5,0$ & $\mathrm{Pla} / \mathrm{V} 8$ \\
\hline 08 & Fert Bokashi Premium & $5,0 / 5,0$ & $\mathrm{~V} 4 / \mathrm{V} 8$ \\
\hline 09 & Microfiltrado & $5,0 / 5,0$ & $\mathrm{~V} 4 / \mathrm{V} 8$ \\
\hline 10 & Fert Bokashi Premium & $5,0 / 5,0 / 5,0$ & $\mathrm{Pla} / \mathrm{V} 4 / \mathrm{V} 8$ \\
\hline 11 & Microfiltrado & $5,0 / 5,0 / 5,0$ & $\mathrm{Pla} / \mathrm{V} 4 / \mathrm{V} 8$ \\
\hline
\end{tabular}

V4 e V8 estádios de desenvolvimento das plantas.

Fonte: Dados da pesquisa.

O delineamento experimetal foi o de blocos ao acaso com 11 tratamentos e 4 repetições. As parcelas foram formadas por 4 linhas de milho com 10,0 $\mathrm{m}$ de comprimento, com espaçamento de $0,5 \mathrm{~m}$ entre linhas, e a área útil das parcelas, as avaliações foram formadas por 2 linhas centrais, excluindose $1,0 \mathrm{~m}$ em cada extremidade.

\subsection{Avaliações}

\subsubsection{Avaliação foliar}

$\mathrm{Na}$ fase de pendoamento foram amostradas duas folhas opostas a espiga, por tratamento e para cada bloco, acondicionadas em sacos plásticos e, posteriormente, levadas para laboratório seccionadas, utilizando-se a parte central da folha, após secas em estufa com circulação de ar forçado a $65{ }^{\circ} \mathrm{C}$, as mesmas foram trituradas em moinho tipo Wile e submetidas à análise para macro e micronutrientes $(\mathrm{N}, \mathrm{P}, \mathrm{K}$, $\mathrm{Ca}, \mathrm{Mg}, \mathrm{S}, \mathrm{B}, \mathrm{Cu}, \mathrm{Fe}, \mathrm{Zinco}, \mathrm{Mn}$ ) (EMBRAPA, 2009).

\subsubsection{Produtividade de grãos}

Para avaliação da produtividade foi realizada colheita manual das espigas das linhas centrais de cada parcela, posteriormente, o material foi levado para o laboratório, em que foi realizada a debulha, os grãos pesados e o resultado extrapolado por $\mathrm{Kg} \mathrm{ha}^{-1}$ e corrigidos para $14 \%$ de umidade.

Além disso, foi realizada a determinação do peso de mil grãos (BRASIL, 2009).

\subsection{Análise estatística}

Após verificar a homogeneidade de variâncias e normalidade os dados foram submetidos à análise de variância e as médias comparadas pelo teste de Tukey a 5\% de probabilidade.

Para as variáveis produtividade e teores $\mathrm{K}, \mathrm{S}, \mathrm{Fe}$ e $\mathrm{Cu}$ foliar, houve efeito da interação entre produto e época de aplicação, sendo desdobrada época dentro de cada produto e quando significativo foi aplicado teste de comparação de médias de Tukey a 5\% de probabilidade. Os dados obtidos foram analisados utilizando o programa SAS (Statistics Analyses Systems).

\subsection{Resultados e Discussão}

A aplicação do bioestimulante Fert Bokashi ${ }^{\circledR}$ ativado e do microfiltrado influenciaram nutricionalmente o crescimento e desenvolvimento da cultivar de milho DKB 290 Pro3 em condições de campo (Quadro 2). Além disso, as plantas apresentaram seus níveis nutricionais proporcionais ao que é recomendado para cultura do milho, conforme Ribeiro et al. (1999), levando em consideração os dois produtos. A aplicação do produto ativado, de acordo com o que é recomendado pelo fabricante, potencializou aumento nos teores de $\mathrm{Fe}, \mathrm{Cu}, \mathrm{K}$ e $\mathrm{S}$, o que influenciou positivamente a produtividade. Vale ressaltar que as diferenças entre macro e micronutrientes foram observadas somente para os nutrientes listados no Quadro 2, não sendo significativas para os demais.

Quadro 2 - Teores de ferro $(\mathrm{Fe})$, cobre $(\mathrm{Cu})$, potássio $(\mathrm{K})$ e enxofre (S) e produtividade de grãos de milho oriundas da aplicação no plantio e nas fases vegetativas V4 e V8 com o bioestimulante Fert Bokashi $^{\circledR}$ ativado

\begin{tabular}{|c|c|c|c|c|c|}
\hline \multirow{2}{*}{$\begin{array}{c}\text { Época da } \\
\text { Aplicação }\end{array}$} & $\mathbf{F e}$ & $\mathbf{C u}$ & $\mathbf{K}$ & $\mathbf{S}$ & $\begin{array}{c}\text { Produtividade } \\
\text { de grãos }\end{array}$ \\
\cline { 2 - 6 } & $\mathbf{( \mathbf { m g ~ d m } ^ { - 3 } )}$ & \multicolumn{2}{|c|}{$\mathbf{( g ~ k g}^{-1} \mathbf{)}$} & $\mathbf{( k g ~ h a}^{-1} \mathbf{)}$ \\
\hline Pla & $\begin{array}{c}323,20 \\
\mathrm{~b}\end{array}$ & $\begin{array}{c}14,10 \\
\mathrm{~b}\end{array}$ & $\begin{array}{c}22,63 \\
\mathrm{ab}\end{array}$ & $\begin{array}{c}2,20 \\
\mathrm{a}\end{array}$ & $10950,00 \mathrm{a}$ \\
\hline PlaV4 & $\begin{array}{c}325,86 \\
\mathrm{~b}\end{array}$ & $\begin{array}{c}14,10 \\
\mathrm{~b}\end{array}$ & $\begin{array}{c}21,56 \\
\mathrm{~b}\end{array}$ & $\begin{array}{c}1,84 \\
\mathrm{c}\end{array}$ & $10830,00 \mathrm{a}$ \\
\hline PlaV4V8 & $\begin{array}{c}331,60 \\
\mathrm{a}\end{array}$ & $\begin{array}{c}14,63 \\
\mathrm{~b}\end{array}$ & $\begin{array}{c}22,31 \\
\mathrm{ab}\end{array}$ & $\begin{array}{c}2,05 \\
\mathrm{~b}\end{array}$ & $11385,00 \mathrm{a}$ \\
\hline PlaV8 & $\begin{array}{c}328,44 \\
\mathrm{ab}\end{array}$ & $\begin{array}{c}16,47 \mathrm{a} \\
\mathrm{a} 4 \mathrm{~V} 8\end{array}$ & $\begin{array}{c}21,69 \\
\mathrm{~b}\end{array}$ & $\begin{array}{c}1,78 \\
\mathrm{c}\end{array}$ & $10548,75 \mathrm{a}$ \\
\hline DMS & $\begin{array}{c}4,88 \\
\mathrm{~b}\end{array}$ & $\begin{array}{c}15,68 \\
\mathrm{ab}\end{array}$ & $\begin{array}{c}23,88 \\
\mathrm{a}\end{array}$ & $\begin{array}{c}2,18 \\
\mathrm{a}\end{array}$ & $9172,50 \mathrm{~b}$ \\
\hline CV (\%) & 12,10 & 10,58 & 9,65 & 10,24 & 15,86 \\
\hline
\end{tabular}

Médias iguais na coluna, seguidas pela mesma letra não diferem entre si pelo teste de Tukey a $5 \%$ de probabilidade.*Pla: aplicação no plantio; V4 e V8 estádios de desenvolvimento das plantas.

Fonte: Dados da pesquisa.

A aplicação do produto no plantio e nos dois estádios de desenvolvimento vegetal (V4 e V8) possibilitou aumento do teor de Fe nas plantas, porém isso não se manteve para os demais nutrientes, havendo oscilações entre aumento de determinado nutriente e período de aplicação (Quadro 2). Para o cobre $(\mathrm{Cu})$, a maior média foi observada quando a aplicação do produto foi no plantio e no estádio V8, para o potássio 
(K) se observou ganho, quando a aplicação foi realizada nos estádios V4 e V8, porém também foram semelhantes quando aplicados somente no plantio e nos estádios V4 e V8. Já o $\mathrm{S}$ apresentou aumento, quando aplicado no plantio e nos estádios V4 e V8.

Estes ganhos nutricionais influenciaram na produtividade de grãos, nos diferentes períodos de aplicação, ficando evidente que o uso do produto ativado no plantio influencia, significativamente, uma vez que as médias foram superiores, quando a aplicação ocorreu no plantio e em um dos estádios de desenvolvimento, sendo maior no conjunto de aplicação: plantio e nos estádios V4 e V8 (Quadro 2).

Para o microfiltrado (Quadro 3) se observa que os mesmos nutrientes ( $\mathrm{Fe}, \mathrm{Cu}, \mathrm{K}$ e $\mathrm{S}$ ) mantiveram os níveis exigidos para cultura, e também incrementaram a produtividade. Quando observada a época de aplicação e a quantificação do nutriente se notou que o Fe se destacou para os quatro períodos de aplicação, com exceção da dispensa do mesmo no plantio e nos estádios V4 e V8, no entanto, para o Cu, este fato foi inversamente proporcional. Já o $\mathrm{K}$ apresentou média superior $\left(21,50 \mathrm{~g} \mathrm{~kg}^{-1}\right)$, quando aplicado no plantio e no estádio V8, porém é semelhante com as médias encontradas, para aplicação no plantio e nos estádios V4 e V8, separadamente.

Quadro 3 - Teores de ferro $(\mathrm{Fe})$ cobre $(\mathrm{Cu})$, potássio $(\mathrm{K})$ e enxofre (S) e produtividade de plantas de milho oriundos da época de aplicação com o microfiltrado do bioestimulante Fert Bokashi ${ }^{\circledR}$

\begin{tabular}{|l|c|c|c|c|c|}
\hline \multirow{2}{*}{ Trat* } & $\mathbf{F e}$ & $\mathbf{C u}$ & $\mathbf{K}$ & $\mathbf{S}$ & $\begin{array}{c}\text { Produtividade } \\
\text { de Grãos }\end{array}$ \\
\cline { 2 - 6 } & \multicolumn{2}{|c|}{$\mathbf{m g ~ d m}^{-3} \mathbf{)}$} & \multicolumn{2}{|c|}{$\mathbf{( g / \mathbf { k g } )}$} & $\mathbf{( k g ~ h a}^{-1} \mathbf{)}$ \\
\hline Pla & $\begin{array}{c}327,58 \\
\mathrm{a}\end{array}$ & $\begin{array}{c}14,36 \\
\mathrm{~b}\end{array}$ & $\begin{array}{c}21,00 \\
\mathrm{ab}\end{array}$ & $\begin{array}{c}1,89 \\
\mathrm{a}\end{array}$ & $10680,00 \mathrm{a}$ \\
\hline PlaV4 & $\begin{array}{c}324,71 \\
\mathrm{a}\end{array}$ & $\begin{array}{c}16,47 \\
\mathrm{~b}\end{array}$ & $\begin{array}{c}20,38 \\
\mathrm{~b}\end{array}$ & $\begin{array}{c}1,75 \\
\mathrm{a}\end{array}$ & $10200,00 \mathrm{~b}$ \\
\hline PlaV4V8 & $\begin{array}{c}297,48 \\
\mathrm{~b}\end{array}$ & $\begin{array}{c}26,73 \\
\mathrm{a}\end{array}$ & $\begin{array}{c}20,38 \\
\mathrm{~b}\end{array}$ & $\begin{array}{c}1,65 \\
\mathrm{a}\end{array}$ & $10747,50 \mathrm{a}$ \\
\hline PlaV8 & $\begin{array}{c}326,72 \\
\mathrm{a}\end{array}$ & $\begin{array}{c}14,50 \\
\mathrm{~b}\end{array}$ & $\begin{array}{c}21,50 \\
\mathrm{a}\end{array}$ & $\begin{array}{c}1,59 \\
\mathrm{a}\end{array}$ & $10387,50 \mathrm{ab}$ \\
\hline V4V8 & $\begin{array}{c}323,85 \\
\mathrm{a}\end{array}$ & $\begin{array}{c}13,57 \\
\mathrm{~b}\end{array}$ & $\begin{array}{c}21,25 \\
\mathrm{ab}\end{array}$ & $\begin{array}{c}1,72 \\
\mathrm{a}\end{array}$ & $10151,25 \mathrm{~b}$ \\
\hline DMS & 29,8 & 10,18 & 1,07 & 0,42 & 524,0 \\
\hline CV & 10,23 & 11,85 & 8,53 & 9,71 & 12,47 \\
\hline
\end{tabular}

Médias iguais na coluna, seguidas pela mesma letra, não diferem entre si pelo teste de Tukey a 5\% de probabilidade.*Pla: plantio; V4 e V8 estádios de desenvolvimento das plantas.

Fonte: Dados da pesquisa.

Os resultados para enxofre não foram significativos, no entanto, os demais influenciaram a produtividade, sendo possível afirmar que para o microfiltrado as médias significativas são quando o produto é aplicado no plantio e nos estádios/V4/V8, no plantio, no plantio/V8, respectivamente.

Quando consideradas as médias dos teores de nutrientes e as épocas de aplicação para cada produto (Fert Bokashi ${ }^{\circledR}$ ativado e microfiltrado) em relação às testemunhas, observouse que o produto ativado, incrementou os teores destes nutrientes (Figura 1).
Figura 1 - Médias do teor foliar de ferro $(\mathrm{Fe})$, potássio $(\mathrm{K})$ e enxofre (S) de plantas de milho oriundas de diferentes períodos de aplicação com o bioestimulante Fert Bokashi ${ }^{\circledR}$ ativado e do seu microfiltrado, em relação à testemunha tratada com água.
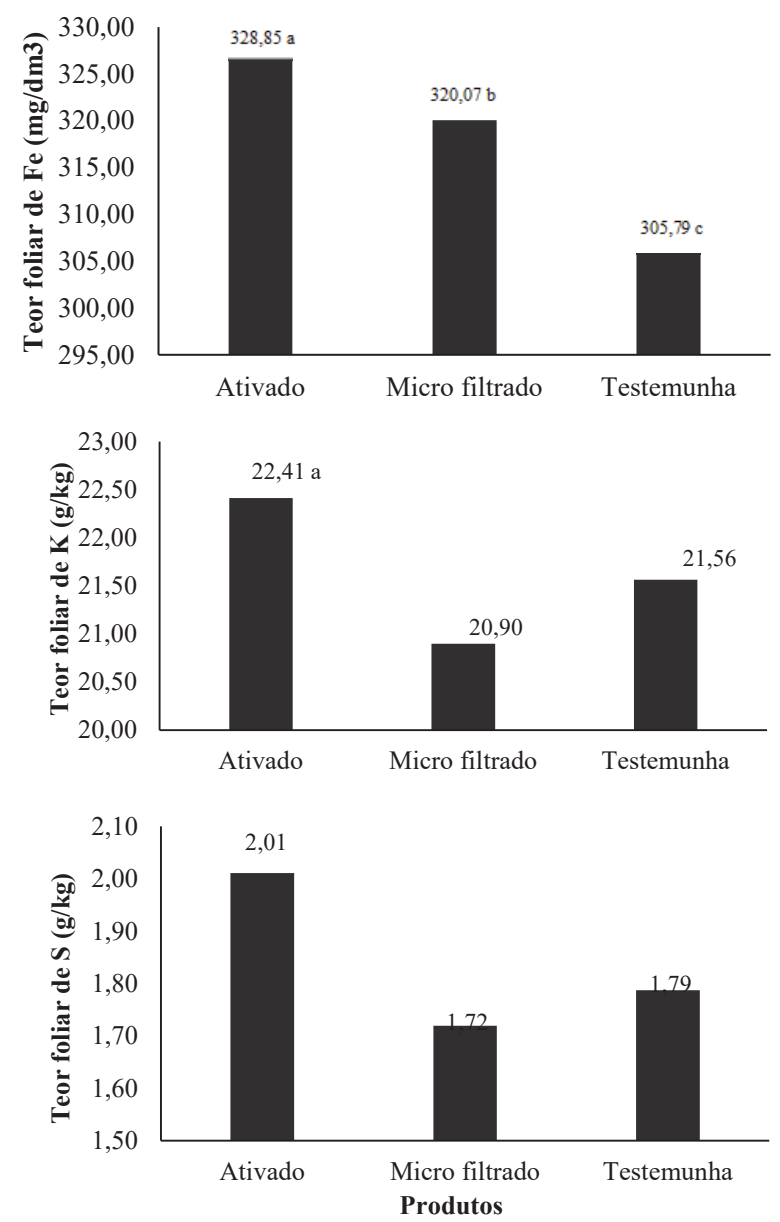

Letras iguais não diferem entre si pelo teste de Tukey a $5 \%$ de probabilidade, para cada gráfico

Fonte: Dados da pesquisa.

De modo geral, o uso do bioestimulante, tanto ativado quanto microfiltrado, influenciou produtividade da cultivar de milho DKB 290 Pro3. De acordo com CropSoluctions (2017), a média da safra na região de São Gabriel do Oeste e de $7502,42 \mathrm{Kg} \mathrm{ha}^{-1}$, e no presente trabalho a média geral de produtividade para o produto ativado foi de $10577,25 \mathrm{Kg}$ ha $^{-1}$ e para o microfiltrado $10433,25 \mathrm{Kg} \mathrm{ha}^{-1}$, comprovando seu efeito como estimulante do crescimento vegetal. Cabe ressaltar que as condições meteorológicas durante a execução do experimento foram ideais para o cultivo.

Um dos mecanismos que podem ter sido incrementados pelo uso deste produto foi a atividade microbiana nativa do solo, uma vez que os resultados superiores observados neste trabalho ocorreram quando da aplicação do produto sobre a palhada, ou seja, no plantio. Fato este comentado por Malik et al. (2012) que indicaram que o uso de biofertilizantes pode aumentar a disponibilidade de nutrientes às plantas pelo processo de mineralização através da matéria orgânica do solo, e atuar indiretamente através do retorno dos nutrientes imobilizados pela massa microbiana. 
Já Prates e Medeiros (2001) afirmaram que a maior importância de um bioestimulante, como fertilizante, não está nos quantitativos dos seus nutrientes, mas na diversidade da composição mineral, que pode formar compostos quelatizados e esses disponibilizados pela atividade biológica e como ativador enzimático do metabolismo vegetal.

Os teores de $\mathrm{Fe}$ encontrados estão dentro do que é recomendado para cultura, para os dois produtos (ativado e microfiltrado) e foram superiores a testemunha (Figura 1). É um elemento muito abundante no Planeta, encontrado na natureza na forma iônica $\mathrm{Fe}^{+3}$ é de fácil oxidação em contato com a molécula $\mathrm{O}_{2}$, um elemento essencial para fotossíntese e um catalisador de enzimas para síntese da clorofila. Também é um ativador que compõe várias enzimas e tem extrema importância para fixação do nitrogênio e na respiração, participa no transporte de elétrons, como citocromos e ferro proteínas não envolvidas na fotossíntese, o ferro é absorvido pelas plantas na forma $\mathrm{Fe}^{2+}$, o ferro também é um cofator para diferentes enzimas ligadas ao tilacoide que protege os cloroplastos de espécies reativas ao oxigênio (LUCENA, 2003; TOTTEY et al., 2003; MURGIA, 2004).

$\mathrm{O}$ teor cobre $(\mathrm{Cu})$ se encontra nas quantidades recomendadas para cultura e a maior média foi observada no produto Fertbokashi ${ }^{\circledR}$ ativado no plantio e estádio V8 e, no microfiltrado, a maior média foi no plantio e nos estádios V4 e V8 (Quadros 2 e 3). É um micronutriente essencial aos vegetais, sendo necessário para funcionamento de várias enzimas, com participação nos compostos enzimáticos e nas reações redox. Está relacionado em vários processos biológicos principais, importante na cadeia que realiza o transporte de elétrons na fotossíntese, na respiração, no metabolismo da parede celular e lignificação. É um elemento essencial na estrutura das proteínas, mitocôndrias e cloroplastos (BURKHEAD et al., 2009; GARCIA et al., 2014; YRUELA, 2013).

O enxofre (S) está na quantidade recomendada para a cultura, o produto ativado foi superior à testemunha, o produto microfiltrado foi inferior à testemunha (Figura 1). Este micronutriente tem significativa importância no desenvolvimento das plantas, pela participação da constituição proteica, síntese da clorofila, formação da ferrodoxina, auxilia na defesa das plantas das pragas e doenças pelos compostos secundários. Participa de numerosos compostos como aminoácidos e proteínas, coenzimas, sulfolipideos, flavonoides, lipídeos, glucosinolatos, polissacarídeos, compostos não saturados, sulfoxidos, alcaloides, nucleotídeos, compostos reduzidos, junto com o $\mathrm{N}$, o S está presente em todas as funções e processos que são parte da vida das plantas, da absorção iônica aos papéis do RNA e DNA, do controle hormonal para o crescimento e a diferenciação celular (ALVAREZ et al., 2007; STIPP; CESARIN, 2010).

$\mathrm{O}$ potássio $(\mathrm{K})$ se encontra na quantidade recomendada pela cultura, o produto ativado foi superior à testemunha, o microfiltrado foi inferior à testemunha (Figura 1). Este elemento na planta não faz parte de compostos específicos, sendo sua formação estrutural. É ativador de diversas enzimas e atua na regulação osmótica das células, da manutenção de água na planta por meio do controle de abertura e fechamento dos estômatos, aumento do tecido vascular pela lignificação, como consequência aumento da resistência contra pragas e doenças, aumento das espessuras das cutículas e parede celular e inibidores de doenças e efeito na permeabilidade das membranas plasmáticas (ERNANI et al., 2007; IMAS, 2013).

Os biofertilizantes baseados em concentrados microbianos enriquecidos são muito utilizados na agricultura como estratégia para incrementar a produtividade, a fertilização biológica tem a finalidade da incorporação de microorganismos ao solo para manutenção do equilíbrio da atividade microbiana, incrementando a fertilidade do solo e dando resistência das plantas às pragas e doenças (MEDEIROS et al., 2003; MEDEIROS, LOPES, 2006).

$\mathrm{Na}$ busca por produtividade das culturas existem fatores que podem afetar seu desenvolvimento que estão relacionados a fatores genéticos, culturais, ambientais e fisiológicos. O uso de fertilizantes contendo macro e micronutriente é fundamental para uma nutrição equilibrada, para que as culturas desempenham suas funções essências, mas o uso de bioestimulantes tem sido largamente utilizado como complemento nas diversas culturas com resultados importantes, em função de efeitos dos bioativadores sobre os hormônios vegetais, que exercem uma função importante no controle do desenvolvimento desses componentes (FLOSS, FLOSS, 2007).

A cultura do milho é de grande importância para compor os sistemas de rotação de culturas no Estado, tanto no plantio de primeira, como na segunda safra, também por apresentar grande valor econômico. $\mathrm{Na}$ atividade agrícola, o grande desafio é produzir alimentos de melhor qualidade, com a preservação do meio ambiente e gerar retorno econômico. Há problemas com pragas, doenças e fatores edafoclimáticos nas regiões produtoras, que interferem no desenvolvimento e na produção das culturas, mas é necessário que as plantas apresentem um sistema radicular bem desenvolvido, tanto no volume e arquitetura, para explorar os recursos disponíveis no solo.

Além de uma adubação equilibrada com macro e micronutrientes, o produtor pode lançar como alternativa o uso de bioestimulante tanto como aplicação via solo, como foliar, para melhorar o desenvolvimento fisiológico da planta, refletindo como um aumento da parte aérea, volume das raízes, contribuindo para melhoria dos atributos físicos como velocidade de infiltração, aeração, armazenagem de água e aceleração da atividade microbiana edáfica. Os biofertilizantes, em sua forma enriquecida com micro-organismos, podem ter uma grande variedade de minerais acrescidos, possibilitando um equilíbrio nutricional e um manejo trofobiótico de pragas e doenças. 


\section{Conclusão}

O FertBokashi ${ }^{\circledR}$ ativado aumenta os teores de ferro, potássio e enxofre e contribui com o aumento produtividade de milho, em condições de campo, e quando aplicado no plantio e nos estádios V4 e V8.

\section{Referências}

ALVAREZ, V.V.H. et al. Fertilidade do solo. Viçosa: SBCS. 2007.

BROCH, D.L.; RANNO, S.K. Fertilidade do solo, adubação e nutrição da cultura da soja. Tecnologia e Produção: Soja e Milho 2011/2012, p. 2-38, 2012.

BRASIL. Ministério da Agricultura, Pecuária e Abastecimento. Regras para Análises de sementes. Brasília: MAPA \ACS, 2009.

BURKHEAD, J. L. et al. Copper homeostasis. New Phytologist. v.182, n.4, p.799-816, 2009. doi: 10.1111/j.14698137.2009.02846.x

COELHO, A. M. et al. Nutrição e adubação do milho. Embrapa Milho e Sorgo, Sistemas de Produção, 2010.

CROPSOLUTIONS. Pesquisa assessoria e consultoria Ltda. Informe técnico CropSolutions 001- avaliação de híbridos de milho safrinha, São Gabriel do Oeste - MS, 2017.

EMBRAPA - Empresa Brasileira de Pesquisa Agropecuária Manual de análises químicas de solos, plantas e fertilizantes. Brasília: Embrapa, 2009.

ERNANI, P. R. et al. Fertilidade do solo Viçosa, $M G$ : Sociedade Brasileira de Ciência do Solo, 2007. p. 551-594.

FLOSS, E.L.; FLOSS, L.G. Fertilizantes organominerais de última geração: funções fisiológicas e uso na agricultura. Rev. Plantio Direto, v. 100, p. 26-29, 2007.

GARCIA, L. et al. Mitochondria and copper homeostasis in plants. Mitochondrion, v.19, p.269-274, 2014. doi: 10.1016/j. mito.2014.02.011

GARCIA-MOLINA, A. et al. The intracellular Arabidopsis COPT5 transport protein is required for photosynthetic electron transport under severe copper deficiency. The Plant J., v.65, n.6, p.848-860, 2011. doi: 10.1111/j.1365-313X.2010.04472.x

IMAS, P. (Comp.). Potássio, o elemento da qualidade na produção agrícola. Horgen: Inter. Potash Inst., 38 p.1-8, 2013. doi: 10.1081/PLN-120024257

LUCENA, J. J. Fe chelates for remediation of Fe chlorosis in Strategy I plants. J. Plant Nutr., v.26, n.10, p.1969-1984, 2003. doi:10.1081/PLN-120024257

LUDKE, J. V. et al. Milho e sorgo: Inovações, Mercado e segurança alimentar. In: CONGRESSO NACIONAL DE MILHO E SORGO. p. 127-146, cap. 5, 2016, Sete Lagoas MG.
Disponível em: ttps://www.researchgate.net/profile/Fa Barbosa/ publication/313376061_Milho_e_sorgo_inovacoes_mercado_e_ seguranca_alimentar/links/5898860e4585158bf6fōb $9 \mathrm{c} 1 / \mathrm{Milho-}$ e-sorgo-inovacoes-mercado-e-seguranca-alimentar.pdf. Acesso em: 13 abr. 2020.

MALIK, D.J. et al. The inactivation of Bacillus subtilis spores at low concentrations of hydrogen peroxide vapour. J. Food Engin, v.114, p.391-96, 2012. doi: 10.1016/j.jfoodeng.2012.08.031

MEDEIROS, B.M. et al. Biofertilizantes líquidos. Rev. Biotec., Ciênc. Desen., v.31, n.2, p.38- 44, 2003.

MEDEIROS, M.B.; LOPES, J.S. Biofertilizantes líquidos e sustentabilidade agrícola. Bahia Agrícola, v.7, n.3, p.24-26, 2006.

MURGIA, I. Arabidopsis thaliana plants overexpressing thylakoidal ascorbate peroxidase show increased resistance to Paraquat - induced photooxidative stress and to nitric oxideinduced cell death. Plant J., v.38, n.6, p.940-953, 2004. doi:10.1111/j.1365-313X.2004.02092.x

PRATES, H.S.; MEDEIROS, M. B. de. Entomopatógenos e biofertilizantes na citricultura orgânica. Campinas: SAA/ Coordenadoria de Defesa Agropecuária, 2001.

RIBEIRO, A.C. et al Recomendações para o uso de corretivos e fertilizantes em Minas Gerais. Comissão de Fertilidade e Solo. p. 281, 359 p, 1999.

SANTOS, V. M. et al. Uso de bioestimulante no crescimento de plantas de Zea mays L., Rev. Bras. Milho e Sorgo, v. 12, n. 3, p. 307-318, 2013. doi: 10.18512/1980-6477/rbms.v12n3p307-318

SANGOI, L. et al. Milho e sorgo: Inovações, mercado e segurança alimentar. In: CONGRESSO NACIONAL DE MILHO E SORGO. p. 49-87, cap. 2. Sete Lagoas MG.

SILVA T. T. A. et al. Qualidade fisiológica de sementes de milho na presença de bioestimulantes. Ciênc. Agrotec. v. 32, p. 840-844, 2008.

SOUZA, J. A. R. et al. Avaliação de frutos de tomate de mesa produzidos com efluente do tratamento primário da água residuária da suinocultura. Rev. Eng. Agri., v. 18, n. 3, p. 198-207, 2010. doi: 10.13083/reveng.v18i3.77

STIPP, S. R.; CASARIN, V. A. Importância do enxofre na agricultura brasileira. Informações Agronômicas, n. 129, p.7, 2010.

TAIZ, L.; ZEIGER, E. Citocininas: reguladores da divisão celular. Fisiologia Vegetal. Porto Alegre: Artmed, 2013.

TOTTEY, S. Arabidopsis CHL27, located in both envelope and thylakoid membranes, is required for the synthesis of protochlorophyllide. Proc. Natl. Acad. Sci PNSA, v. 100, n. 26, p. 1-6, 2003. doi: 10.1073/pnas.2136793100

YRUELA, I. Transition metals in plant photosynthesis. $J$. Metallomics, v.5, n. 9, p. 1-20, 2013. doi: 10.1039/c3mt00086a 